\title{
Current trends in the management of ocular symptoms in Adamantiades-Behçet's disease
}

This article was published in the following Dove Press journal:

Clinical Ophthalmology

15 October 2009

Number of times this article has been viewed

\section{Fouad R Zakka' \\ Peter Y Chang' \\ Gian P Giuliari' \\ C Stephen Foster ${ }^{1,2}$}

'Massachusetts Eye Research and Surgery Institution (MERSI), Cambridge, Massachusetts, USA; ${ }^{2}$ Department of Ophthalmology, Harvard Medical School, Boston, Massachusetts, USA
Correspondence: C Stephen Foster Massachusetts Eye Research and Surgery Institution, 5 Cambridge Center, 8th Floor, Cambridge, MA 02142, USA

$\mathrm{Tel}+\mathrm{I}(617) 62 \mathrm{I}-6377$

Fax +I (6I7) 494-1430

Email sfoster@mersi.us
Abstract: Adamantiades-Behçet's disease (ABD) is a multisystemic vasculitic disease. It is most prevalent in the Eastern Mediterranean countries and the Eastern region of Asia. Its effect on the eye can range from mild to debilitating, resulting in total blindness. A necrotizing and obliterative vasculitis affects both arteries and veins of organs. Recurrent attacks of uveitis, oral aphthous ulcers, skin lesions, and genital ulcers are common. Topical and systemic corticosteroids have been the mainstay in the treatment of ocular inflammation for many years; however, due to the several known side effects of corticosteroids and thanks to scientific advances, more novel approaches to ABD treatment have been emerging. Antimetabolites such as methotrexate and azathioprine have been utilized with the latter showing positive results. Chlorambucil has been utilized effectively for ocular manifestations of $\mathrm{ABD}$. Interferon alpha has shown encouraging results in the management of refractory ocular inflammation associated with $\mathrm{ABD}$, either alone or in combination with other immunosuppressive agents. Surgical interventions to deal with complications from ABD can be safely done if adequate control of inflammation is achieved peri-operatively. Early detection and aggressive treatment, when needed, have proven to be essential in the management of this relentlessly explosive disease.

Keywords: Adamantiades-Behçet's disease, Behçet's disease, ocular inflammation, uveitis, immunomodulatory therapy, immunosuppressive therapy

\section{Introduction}

\section{Historical context}

Adamantiades-Behçet's disease (ABD) is a chronic, relapsing systemic vasculitis that afflicts organs encompassing the eye, skin, gastrointestinal tract, joints, genitalia, and central nervous system. To date, a clear etiology of the disease has not been identified. Described possibly by Hippocrates in the 5th century BC, ${ }^{1}$ it is named after Benedictos Adamantiades, a Greek ophthalmologist, and Hulusi Behçet, a Turkish dermatologist, who in the 1930s separately published on their patients with the findings of recurrent iritis as well as oral and genital ulcers. Although Adamantiades had presented his case report ${ }^{2}$ seven years prior to Behçet, the disease is widely referred to as Behçet's disease primarily due to the popularity of the German medical literature in which the latter presented his case series of three patients. ${ }^{3}$ To properly reflect the importance of the contribution both of these physicians made to the recognition of this devastating disease, this article will adopt the name Adamantiades-Behçet's disease (ABD). 


\section{Epidemiology}

ABD is most commonly found in countries of the Eastern Mediterranean and the Eastern edge of Asia. Its predominant distribution between the $30^{\circ}$ and $45^{\circ}$ north latitudes roughly correspond to the old Silk Road utilized for trades between the East and Europe. ${ }^{4}$ While its prevalence is much higher in countries such as Turkey, Iran, and Japan, ABD accounts for only $0.2 \%$ to $0.4 \%$ of uveitis cases in the United States, with a prevalence of 4 patients per 1 million population. ${ }^{5,6}$

Earlier reports from Asia and the Mediterranean basin showed a male preponderance of $\mathrm{ABD} ;{ }^{5,7,8}$ however, more recent reports suggest a more equal distribution between sexes. It appears that the complete type of ABD (see Clinical features below) is more common in males, while the incomplete type has a 1:1 male-to-female ratio. ABD has been reported in all ages, but mostly between 25 and 35 years. In general, younger age and male gender are associated with more disease severity.

\section{Genetics}

Due to the increased prevalence in certain racial groups, it is clear that genetics plays an important role in the pathogenesis of ABD. HLA-B5 (and its subtype HLA-B51), HLA-B12, HLA-B27, and HLA-A26 have all been implicated in $\mathrm{ABD} ;{ }^{9-11}$ of these, HLA-B5 appears to be associated with the worst ocular prognosis. ${ }^{12}$ On the other hand, HLA-DR1 and HLA-DQw1 seem to confer resistance to the disease. ${ }^{13}$

\section{Pathology and immunology}

The pathology of ABD varies depending on the location of the lesions, but its principal features include perivascular infiltrates of lymphocytes and mononuclear cells, and swelling, proliferation and subsequent fibrinoid necrosis of small blood vessels, especially venules. Excessive number of mast cells may be found in the recurrent mucocutaneous ulcers. ${ }^{14}$ Demyelination is the most common finding in the brain. ${ }^{15}$

Ocularly, acute uveitis is characterized by diffuse infiltration of neutrophils, followed by lymphocytes, monocytes and mast cells in the iris, ciliary body and choroid. When the disease becomes chronic and recurrent, the presence of increased collagen can lead to iris atrophy, posterior synechiae, cyclitic membrane formation, and choroidal thickening. Retinal vasculitis, which involves veins more than arteries, is typified by significant infiltration of leukocytes and plasma cells in and around blood vessels and deeper into the retinal tissue. Although retinal pigment epithelium destruction is minimal, the photoreceptor layers are often damaged. In more advanced vasculitis, fibrosis of the vessels can lead to the obliteration of the vascular structures. In addition, the vasculitic process may result in optic neuritis, ischemia, and even atrophy.

The T lymphocyte is the predominant cell type in the immunopathogenesis of ABD. The early lesions in ABD resemble a delayed-type hypersensitivity reaction (type IV), while the late lesions correspond to an immune-complex type reaction (type III). Whether vessel inflammation is driven by immune complexes is debatable, however, as immunoglobulins are not typically found in the vessel walls of ABD patients.

\section{Clinical features}

The diagnosis of ABD is based on clinical findings. Two separate diagnostic systems currently exist: one by Behçet's Research Committee of Japan in 1974 (Table 1), ${ }^{16}$ and the other by the International Study Group for Behçet's Disease in 1990 (Table 2). ${ }^{17}$ The major difference between the two systems is that the former emphasizes ocular symptoms, while the latter stresses the importance of oral aphthae (thus, we prefer the Japanese system in our care of ophthalmic patients).

\section{Systemic manifestations}

Oral aphthous ulcer is the most common finding in ABD. These lesions of 3 to $15 \mathrm{~mm}$ diameter are recurrent and very painful. The lesions can be found anywhere in the oral cavity, including the lips, gums, tongue, palate, uvula, and posterior pharynx.

Table I Diagnostic criteria of Adamantiades-Behçet's disease (ABD) suggested by Behçet's Research Committee of Japan

Major criteria

Recurrent oral aphthous ulcers

Recurrent genital ulcers

Skin lesions

Ocular inflammation

Minor criteria

Arthritis

Gastrointestinal tract ulceration

Epididymitis

Vasculitis/vasculopathy

Neuropsychiatric symptoms and signs

ABD types

Complete (4 major)

Incomplete (3 major, or ocular inflammation with I other major)

Suspect (2 major, no ocular inflammation)

Possible (I major)

Modified from Newman NM, Hoyt WF, Spencer WH. Macula-sparing monocular blackouts: Clinical and pathologic investigation of intermittent choroidal vascular insufficiency in a case of periarteritis nodosa. Arch Ophthalmol. 1974; 91(5):367-370. ${ }^{134}$ 
Table 2 Diagnostic criteria of Adamantiades-Behçet's disease suggested by the International Study Group for Behçet's disease

Recurrent oral aphthous ulcers (at least 3 times a year) and 2 of the

following:

Recurrent genital ulcers

Skin lesions

Ocular inflammation

Positive pathergy test (Behçetine test) ${ }^{\mathrm{a}}$

apathergy test is performed by inserting a 20-guage or smaller needle (no injection) $5 \mathrm{~mm}$ obliquely into the skin of the flexor aspect of the forearm. The test is positive if there is an indurated erythematous papule or pustule with $>2 \mathrm{~mm}$ diameter after 24 to 48 hours.

Modified from Gold DH. Ocular manifestations of connective tissue (collagen) diseases. In: Tasman W, Jaeger AE, editors. Duane's Clinical Ophthalmology. Philadelphia: J.B. Lippincott. 1989;5: 17-19.135

They typically last 7 to 10 days and resolve spontaneously, though some patients never fully recover before the next bout of ulcers appears. Skin eruptions resembling acne vulgaris or folliculitis are common cutaneous findings, especially above the neck. Erythema nodosum can be found not only on the tibia (as classically seen in sarcoidosis), but also on the face, neck, and buttock. Genital ulcers are another common mucocutaneous finding of ABD. They can occur on the penis, scrotum, vulva, and vaginal mucosa; at times, they are located in the perianal areas. Although epididymitis is common in $\mathrm{ABD}$, urethritis is not a known feature, which may be helpful in differentiating the condition from reactive arthritis. Furthermore, superficial thrombophlebitis can occur on both upper and lower extremities, and these lesions should be evaluated very carefully as they may indicate a more widespread disease.

Neurologic involvement (neuro-ABD) is one of the most serious complications of $\mathrm{ABD}$. The reported frequency of CNS involvement in ABD ranges from 3\% to $10 \% .{ }^{8}$ Its manifestations are wide-ranging and nonspecific: migrainelike headaches, stiff neck, cranial nerve palsies, hemiparesis, cerebellar ataxia, pyramidal and extrapyramidal signs, seizures, peripheral neuropathies, mental status change, audiovestibular deficits, and many more have all been reported.

Arthritis occurs at some point in approximately half of ABD patients, with lower extremity joints most commonly affected. It can be monoarticular, oligoarticular, or polyarticular, but it is typically not chronic or destructive. Other systemic features of $\mathrm{ABD}$ have been documented in the cardiovascular, pulmonary, gastrointestinal, and renal systems.

\section{Ocular manifestations}

Ocular symptoms occur in $43 \%{ }^{18}$ to $72 \%{ }^{19}$ of ABD patients and affect males more commonly than females. They are not usually the first presenting manifestations of $\mathrm{ABD}$ (only in about 10 to $13 \%$ of the cases). ${ }^{20,21}$ The time between oral and genital lesions and eye involvement is estimated to be 3 to 4 years. ${ }^{22}$ Although the ocular disease may initially be unilateral, it almost always progresses to both eyes.

Anterior uveitis of ABD is nongranulomatous. It is explosive in nature but may resolve in 2 to 3 weeks without any therapy. The presenting symptoms and signs include periorbital pain, blurry vision, conjunctival injection, ciliary flush, anterior chamber cells and flare, and fine keratic precipitates. Mobile hypopyon, which moves as a patient changes head positions, is a classic finding, although it is exceedingly rare today likely due to earlier diagnosis and treatment; Tugal-Tutkun et al found hypopyon in only $12 \%$ of 1567 eyes. ${ }^{27}$ At times, the hypopyon is not immediately visible but may be discovered in the angle via gonioscopy (termed angle hypopyon). Of note, hypopyon is also found in HLA-B27-associated anterior uveitis; however, it is usually less mobile than that found in ABD. Repeated attacks in the anterior chamber result in structural damages such as anterior and posterior synechiae and iris atrophy. Furthermore, in the case of chronic posterior segment inflammation, rubeosis may become apparent and signify a poor ocular prognosis.

In the posterior segment, vitreal inflammatory cells are always present during acute attacks. Chronic inflammation of the vitreous frequently leads to posterior vitreous detachment. The most prominent retinal change is obliterative, necrotizing vasculitis that afflicts both arteries and veins; evident on the fundoscopic exam are engorged veins, perivascular sheathing (veins usually before arteries), intraretinal and vitreous hemorrhage, macular edema, retinal ischemia and infarct, disc swelling, and chorioretinal scarring. Repeat vasculitic attacks ultimately result in permanent vascular occlusion (central or branch retinal vein or artery occlusion) and tissue hypoxia, which induces neovascularization of the optic nerve (neovascularization of the disc, or NVD) or elsewhere (NVE). When only posterior segment inflammation is present, the patient typically relates painless decrease in vision with a sudden increase in floaters.

As with most chronic intraocular inflammation, $\mathrm{ABD}$ uveitis is complicated by cataracts and glaucoma, both of which result from the inflammation itself and the chronic corticosteroid therapy that is all too often employed in the patients. Clearly, the ocular involvements in ABD have extremely dire consequences, as each recurrence damages the eye. Therefore, it is essential for a clinician to diagnose the disease early and begin aggressive treatments, which usually comprise systemic immunomodulatory medications. Even as a patient's disease enters remission, one must not be 
complacent because recurrence is the rule in ABD. Regardless of the disease activity, patients should always have regular slit-lamp exams. Angiographic and electrophysiological studies are also useful in monitoring posterior segment changes and prognosticating visual outcomes.

\section{Treatment}

\section{Corticosteroids}

For many years, topical and systemic corticosteroids have been the gold standard in the treatment of ocular inflammation, contributing immensely to the treatment of these often difficult patients. Prolonged corticosteroid therapy, however, is associated with a broad spectrum of local and systemic side effects, such as cataracts, glaucoma, systemic hypertension, hyperglycemia, weight gain, peptic ulcers, Cushingoid syndrome, psychosis, and many, many others. Furthermore, it is not uncommon for ABD to become refractory to corticosteroids, with progressive loss of vision and the eventual need for additional therapeutic options. ${ }^{23}$

\section{Systemic corticosteroids}

The use of systemic corticosteroids in ABD is controversial. If they are to be used, they are preferred in cases of posterior inflammation, panuveitis, retinitis and/or severe anterior chamber and intermediate inflammation with multiple exacerbations that are poorly responsive to topical and/or periocular corticosteroids. In these cases, they should be given in high doses such as oral prednisolone (1 to $2 \mathrm{mg} / \mathrm{kg}$ daily) given in a single morning dose after breakfast and/or as an intravenous dose as a pulse methylprednisolone ( $1 \mathrm{~g}$ daily for 3 consecutive days). After disease control is attained, corticosteroids should be tapered gradually to a maintenance dosage of 15 to $20 \mathrm{mg}$ daily.

Even though systemic corticosteroids have proven effective in the treatment of acute ocular attacks in patients with $\mathrm{ABD}$, one should try to avoid the chronic use of these agents in an attempt to reduce the associated side effects. Furthermore, steroid-resistance can occur in patients with posterior segment involvement, ${ }^{24,25}$ and corticosteroids may be associated with retinal thrombosis. ${ }^{26,27}$

Regardless of the fact that some ophthalmologists never give systemic corticosteroids due to the belief of a worse long-term prognosis, we believe that it is appropriate to employ a short course of high-dose systemic corticosteroids to an existing regimen of immunosuppressive drugs in cases of acute posterior segment involvement, in an effort to eradicate all inflammation while waiting for other medications to take full effects.

\section{Topical corticosteroids}

The use of topical corticosteroids is usually applied to mild episodes of anterior and intermediate inflammation. These agents may be given as drops during the day and ointment at bedtime. The use of the so-called stronger corticosteroids such as prednisolone $1 \%$ and/or dexamethasone is preferred over weaker ones such as fluorometholone. Regardless of the route of administration, topical corticosteroids should be given at a large dose initially and then tapered as soon as the inflammation is brought under control, possibly over a period of several weeks once the inflammation is controlled. It is not uncommon that after the corticosteroids are withdrawn the inflammation may recur. At the Massachusetts Eye Research and Surgery Institution, if the inflammation is mild, we usually start therapy with one drop 4 times a day. We increase the frequency in more severe cases. These drops are then gradually tapered 1 drop every week once the inflammation is controlled.

Once the inflammation is suppressed and the therapy has been discontinued, it is prudent to follow the patient to ensure the absence of recurrence. It is not uncommon that the inflammation recurs upon tapering of corticosteroids. To monitor the anterior chamber inflammatory status, one should use the classification put forth by the Standardization of Uveitis Nomenclature (SUN) Working Group. ${ }^{28}$ In our practice we do not chase every single cell; we treat inflammatory cell reaction equal or greater than $1+$.

\section{Periocular corticosteroids}

This route of administration is offered to patients with more severe inflammation, especially with posterior uveitis, vitritis and macular edema. Several studies have demonstrated the benefit of periocular corticosteroid injections in the treatment of uveitic macular edema. ${ }^{29-32}$ We believe that periocular corticosteroids may be especially beneficial in patients with unilateral disease, to whom they could be administered alone or in combination with systemic corticosteroid and/or a steroidsparing agent. Periocular corticosteroids may also be offered to severe anterior chamber inflammation with poor response to topical corticosteroids. Depot agents such as triamcinolone acetonide are preferred over other types of corticosteroids such as prednisolone and dexamethasone, as they are able to achieve a longer lasting anti-inflammatory effect.

\section{Azathioprine}

Azathioprine (AZA) is an imidazolyl derivative of 6-mercaptopurine. It is metabolized to 6-mercaptopurine, and then to thioinosine-5-phosphate, which is a purine analogue. The latter interferes with DNA, RNA, and protein synthesis 
by acting as a false precursor for adenine and guanine synthesis. Azathioprine also acts by suppressing circulating T-cells, selectively decreasing monocyte precursors, suppressing delayed hypersensitivity reactions, and inhibiting T-lymphocyte function. ${ }^{33}$

Kötter and associates evaluated the efficacy of different treatment strategies in controlling the several organ manifestations of $\mathrm{ABD} .{ }^{34}$ The results revealed that in patients with uveitis (posterior or panuveitis), AZA was successfully used to achieve complete remission in 8 of 10 cases when combined with CSA and corticosteroids. Hamuryudan and colleagues conducted a two-year randomized, placebo-controlled, double-blind trial studying the effect of AZA therapy on long-term prognosis in ABD. ${ }^{35}$ The authors followed 73 ABD patients, 48 of whom had ocular involvement and 25 who did not. It was found that AZA was superior to placebo in preventing eye diseases in patients without ocular involvement. In addition, a decrease in hypopyon uveitis episodes was observed in patients with ocular involvement. Other studies have also found that early AZA treatment was effective in improving the long-term visual prognosis of $A B D$ patients and preventing new ocular involvement. ${ }^{36-38} \mathrm{~A}$ study by our group showed more equivocal results. ${ }^{38}$ We found that only 3 of 8 patients achieved control of ocular inflammation in combination with cyclosporine or systemic corticosteroids. As such, we do not consider azathioprine to be the most effective drug for the treatment of ABD.

The most common side effect of AZA is gastrointestinal upset. Myelosuppression is a serious side effect, and is reversible and dose-related. Liver enzyme abnormalities are observed in less than $2 \%$ of patients. ${ }^{33}$

\section{Methotrexate}

Methotrexate was first used in 1958 to treat leukemia. It is a folic acid analogue that competitively binds and inactivates the enzyme dihydrofolate reductase (DHFR) which plays a key role in converting dietary folic acid to reduced, metabolically active folates (dihydrofolate and tetrahydrofolate). Folate plays a role in the metabolism of histidine, thymidylate and purine synthesis, and in the conversion of homocysteine to methionine. This along with its antiangiogenic properties, cellular and humoral immunosuppression, and inhibition of cytokine production may account for the therapeutic effect of low-dose methotrexate. ${ }^{33,39}$

The bioavailability of methotrexate is $100 \%$ when given intravenously. It also exhibits a high bioavailability when given in low doses orally, intramuscularly, and subcutaneously. Metabolism takes place in the liver and all the metabolites are cleared renally. ${ }^{33}$ Folinic acid is used to protect or shield normal cells from the toxic effect of methotrexate when used in high doses. Folinic acid remains active without the need for reduction by DHFR. It functions by restoring thymidylate, methionine, and purine biosynthesis. The activity of folinic acid is impervious to the presence of methotrexate in the system. ${ }^{39}$

Methotrexate has been used in treating a large number of ocular inflammatory diseases. The evidence regarding methotrexate use in ABD uveitis is scant. It has been shown that methotrexate is not entirely effective for posterior uveitis, but it is more potent for anterior uveitis when used at a low dose of 7.5 to $25 \mathrm{mg}$ weekly. ${ }^{40-42}$

Methotrexate is mostly well-tolerated and side effects improve with reducing dosage. The most common side effects are nausea, vomiting, diarrhea, anorexia, and weight loss. Cutaneous vasculitis, urticaria, alopecia, photosensitivity, and cutaneous nodules are also side effects of low-dose methotrexate. ${ }^{43}$ Hepatotoxicity is a likely side effect and alcohol consumption should be avoided by patients in treatment with methotrexate. Duration of therapy and age are risk factors for hepatotoxicity, and abnormal liver enzymes are seen in $15 \%$ of patients. ${ }^{44,45} \mathrm{~A}$ study by our group on the long-term risk of malignancy among patients treated with immunosuppressive agents for ocular inflammation showed that methotrexate has virtually no long-term carcinogenic effects. ${ }^{46}$ Pregnant women are not eligible for methotrexate treatment as it is a definite teratogen. ${ }^{33}$

\section{Colchicine}

Colchicine is an anti-inflammatory plant alkaloid and is well-known in the treatment of gout. ${ }^{47}$ It acts by inhibiting neutrophil chemotaxis by binding to microtubular proteins and interfering with the function of the mitotic spindle. ${ }^{48-50}$ Consequently, the migration of granulocytes, which are responsible for the release of lactic acid and inflammatory enzymes to inflammation sites, is inhibited. Through the prevention of spindle formation, it appears that colchicine can also act as an antimitotic agent, stopping cell division in metaphase.

Colchicine is effective in the treatment of ocular manifestations of $\mathrm{ABD}$, both alone or in combination with other drugs. ${ }^{51-55}$ One earlier study showed that 104 of 131 patients with ABD were responsive to colchicine therapy. ${ }^{54}$ Colchicine has been successful in the treatment of anterior uveitis at a dosage of $1 \mathrm{mg}$ daily; however its efficacy in severe posterior uveitis is yet to be determined. ${ }^{56,57}$ Masuda and associates reported that colchicine was inferior 
to cyclosporine in treating the ocular manifestations of ABD, in addition to oral skin lesions, aphthous ulcer, and genital lesions. ${ }^{58}$ Nonetheless, colchicine and cyclosporine may be used in combination. ${ }^{59}$

Colchicine is usually well tolerated in moderate doses, gastrointestinal side effects being the most common. Nephrotoxicity, hemorrhagic gastroenteritis, ascending paralysis of the central nervous system, vascular damage, and muscular depression may be caused by acute toxicity, while azospermia, myopathy, aplastic anemia, and agranulocytosis may occur in chronic use. ${ }^{60}$

\section{Chlorambucil}

Chlorambucil, a nitrogen mustard derivative, is widely used in the treatment of lymphomas. It acts by alkylating purine bases. This causes DNA strands to undergo intrastrand crosslinking as well as DNA-to-protein crosslinking, which disrupts DNA replication, transcription, and nucleic acid function, ultimately leading to apoptosis. ${ }^{33}$ Chlorambucil has a high absorption in the gut, reaching peak concentration within one to two hours. ${ }^{61}$ Phenylacetic acid mustard, the active metabolite, is produced in the liver, and is hydrolyzed into an inactive compound, along with chlorambucil, and excreted renally. The half-life of phenyl acetic mustard is 145 minutes and that of chlorambucil is 92 minutes.

Two approaches exist for the use of chlorambucil in uveitic patients. The first, described as the traditional method, consists of administering 0.1 to $0.2 \mathrm{mg} / \mathrm{kg}$ body weight of the medication daily. Treatment would continue for 1 year after the disease has been controlled so as to achieve "long-term, drug-free remission." ${ }^{2}$ The second approach consists of administering short-term, high dose therapy. One would begin at $2 \mathrm{mg}$ daily for 1 week and increase the dosage by $2 \mathrm{mg}$ daily each week thereafter. The increase in dosage would continue either until inflammation is controlled or a white blood count of below 2,400 cells per microliter or a platelet count below 100,000 cells per microliter is achieved. This treatment would typically be carried out for 3 to 6 months but discontinued immediately in case of bone marrow toxicity. ${ }^{63}$

A study by Mudun and coworkers evaluated the responsiveness of patients with $\mathrm{ABD}$ uveitis to short-term chlorambucil therapy. ${ }^{64}$ The study population consisted of 44 patients and efficacy of chlorambucil was evaluated by measuring the frequency of disease flare-ups per year and the longest time period between flare-ups while in treatment. The results revealed that the mean frequency of attacks had decreased from $4.9 \pm 2.3$ to $0.9 \pm 1.4(P<0.0001)$ and the mean longest period between the attacks was prolonged from $4.4 \pm 2.3$ months to $25.7 \pm 23.1$ months $(P<0.0001)$. Goldstein and associates studied 53 patients with uveitis treated with short-term high-dose chlorambucil. ${ }^{65}$ The treatment period ranged from 2 to 9 months. Seventeen patients out of the total population had ABD-associated uveitis. Thirteen of those patients (76\%) achieved sustained remission after initial treatment. Our group conducted a noncomparartive case series on 28 patients with chronic noninfectious uveitis treated with chlorambucil. ${ }^{66}$ Of those patients, 7 were diagnosed with ABD. Results showed that all 7 patients responded to treatment; however, only 2 of 7 had an ocular and systemic response. Two of 7 patients responded both ocularly and systemically but later relapsed. Three of 7 patients showed an ocular response but failed to respond systemically. The study demonstrated that chlorambucil is a safe treatment when administered and monitored expertly.

Bone marrow depression is a serious side effect of chlorambucil therapy. However, this can be reversed by reducing the dosage or discontinuing the treatment. Sterility is another major concern related to chlorambucil therapy. Men are seemingly more susceptible to sterility than women. A relationship has been described between cumulative dose of therapy and gonadal effect of chlorambucil. ${ }^{66}$ It has been shown that doses less than $8.2 \mathrm{mg} / \mathrm{kg}$ in children and $6.1 \mathrm{mg} / \mathrm{kg}$ in adults do not affect fertility. ${ }^{67-70}$ With the option of sperm cryopreservation now readily available, we believe that sterility is a risk worth taking in the quest to prevent blindness in ABD patients.

\section{Cyclophosphamide}

Cyclophosphamide is a nitrogen mustard derivative similar to chlorambucil. It is designed to target neoplastic cells more selectively than healthy cells. Phosphoramide mustard is the active compound which inhibits DNA and RNA synthesis and results in apoptosis. Cyclophosphamide acts on both primary and established cellular and humoral immune responses, suppressing delayed-type hypersensitivity, mixed lymphocyte reactions, mitogen-induced and antigen-induced blastogenesis, and production of cytokines. ${ }^{39}$ The drug is primarily excreted renally with less than $25 \%$ remaining chemically unaltered in the urine. ${ }^{71,72}$ The drug can be administered both orally and intravenously and is well tolerated in the gut. Nonetheless, we prefer the intravenous method for ease of saline flushing and shorter time of exposure in the body.

Not much evidence exists regarding the effectiveness of cyclophosphamide in ABD-associated ocular inflammatory disease, especially as a monotherapy. We usually select chlorambucil over cyclophosphamide for the treatment of $\mathrm{ABD}$ 
ocular disease, unless urgent care is required, in which case we employ intravenous cyclophosphamide. As with chlorambucil, cyclophosphamide can result in serious adverse effects if not dosed and monitored expertly.

\section{Thalidomide}

Thalidomide is a derivative of glutamic acid and was synthesized in the 1950s. It was originally used as an antihistamine and anticonvulsant, and subsequently a sedative and anti-emetic. Tragically, it was later discovered that thalidomide was highly teratogenic and was linked to thousands of birth defects worldwide. This resulted in the drug being pulled off the market, and it did not gain FDA approval until nearly 40 years later. ${ }^{73}$

Thalidomide is reported to have an immunomodulatory, anti-inflammatory, and anti-angiogenic effect. The proposed mechanism of its immunomodulatory/anti-inflammatory action is that thalidomide selectively inhibits the production of tumor necrosis factor-alpha (TNF- $\alpha$ ) in monocytes by the accelerated degradation of TNF- $\alpha$ mRNA and the reduction of its half-life. In addition, the drug also results in the decrease of neutrophil migration to the site of inflammation and the reduction of polymorphonuclear phagocytosis. Thalidomide also co-stimulates the production of T-lymphocytes and, as such, proves useful in lowering TNF- $\alpha$ levels while maintaining normal immunity. ${ }^{59,74}$

Thalidomide's anti-angiogenic activity has been demonstrated in solid tumors, in the control of gastric bleeding and rabbit-model corneal neovascularization. When thalidomide was studied in a mouse-model retinopathy of prematurity-associated neovascularization and retinopathy, it was not effective. ${ }^{74-79}$

In treating $\mathrm{ABD}$, thalidomide appears to have favorable results in orogenital lesions, arthritis, and erythema nodosum. The results in uveitis are not as encouraging. ${ }^{80-82}$ In 1986, Hamza studied the use of thalidomide in 30 male patients with ABD. ${ }^{83}$ Twenty-six of 27 patients with oral ulcerations showed improvement with therapy. Four patients with erythema nodosum had resolution of the lesions within 7 to 10 days after thalidomide was initiated; once the medication was purposely withdrawn, all 4 patients flared up within a week. Sixteen patients had uveitis, and the disease was active in 11 patients at the time the treatment was initiated. Three patients with uveitis had total regression of inflammation within 1 to 3 months. In 4 patients inflammation was stable; it did not improve or worsen. Four patients experienced a deterioration of their uveitis requiring the use of corticosteroids.

The most notorious side effect of thalidomide is teratogenecity, with phacomelia being the best recognized congenital abnormality. There have also been reports of neural tube abnormalities, micro-ophthalmia, duodenal stenosis, and mid-line hemangiomas. ${ }^{84}$ Peripheral neuropathy is another serious side effect resulting in painful, symmetrical paresthesias of upper and lower extremities as well as sensory loss. ${ }^{85}$

\section{Tacrolimus}

Tacrolimus, also known as FK506, is a macrolide analogous to cyclosporin A. It is a calcineurin inhibitor isolated from the fungus Streptomyces tsukubaensis and is frequently used in organ transplantation. Like cyclosporine, it binds to the intracellular FK-binding protein and then associates with calcineurin. This ultimately leads to the inhibition of TNF- $\alpha$ and GM-CSF production. ${ }^{33,59,86}$

Tacrolimus is poorly absorbed orally. Its absorption form the gastrointestinal tract is incomplete, variable, and limited when taken with food. It is metabolized hepatically via the cytochrome P450 system, and fecal elimination accounts for over $90 \%$ of elimination. ${ }^{33,39}$ The drug may also be given intravenously, but most uveitis patients receive it orally. The initial dosage for uveitis recommended by an expert panel is $0.05 \mathrm{mg} / \mathrm{kg}$ daily with a maximum dosage of $0.3 \mathrm{mg} / \mathrm{kg}$ daily.

Tacrolimus has been used to treat ABD-associated uveitis in patients who have failed cyclosporine. ${ }^{87-89}$ Sloper and colleagues have studied the efficacy of tacrolimus in patients who did not respond to cyclosporine treatment. ${ }^{90}$ Six patients with posterior uveitis - 3 associated with ABD - refractory to cyclosporine were treated with tacrolimus. The 3 patients with $\mathrm{ABD}$ as well as 2 other patients (1 with microscopic polyangiitis and 1 with pars planitis) showed improvement in uveitis with the therapy. Hogan and associates recently studied tacrolimus treatment in 62 patients with noninfectious uveitis. ${ }^{91}$ It was found that the drug's efficacy was sustained on a long-term basis with an excellent cardiovascular risk profile.

The side effects of tacrolimus are similar to those of CSA in terms of gastrointestinal disturbance, hypertension, neurotoxicity, and nephrotoxicity. It differs from CSA in that it is diabetogenic. In addition, the degrees of hypertrichosis, hyperlipidemia, gingival hypertrophy and coarsening of the features are less with tacrolimus. ${ }^{59}$

\section{Interferon-alpha}

Interferon-alpha (IFN- $\alpha$ ) is a cytokine initially produced for its antiviral properties. It was the first cytokine to be produced in the recombinant form. Since its production, it has been studied for multiple sclerosis and $\mathrm{ABD}$ due to its immunomodulatory 
capabilities. IFN- $\alpha$ and IFN- $\beta$ are both type I interferons. IFN- $\alpha$ is produced by leukocytes and IFN- $\beta$ is produced by fibroblasts, and they are both functionally similar. They modulate the production of antibodies and inhibit lymphocyte proliferation as well as delayed-type hypersensitivity, all the while enhancing T-cell and NK-cell cytotoxicity. The drug

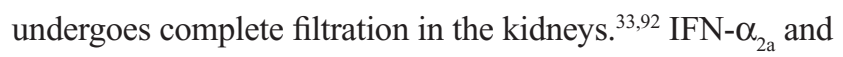
IFN- $\alpha_{2 b}$ are commercially available as injections.

Studies on IFN- $\alpha$ have shown encouraging results, especially in the treatment of refractory ocular inflammation associated with $\mathrm{ABD}$. In addition, IFN- $\alpha$ has also proven effective when combined with other immunomodulatory agents and corticosteroids. ${ }^{59,93}$ Tugal-Tutkun and associates studied 44 Turkish patients who were treated with IFN- $\alpha_{2 \mathrm{a}}{ }^{94}$ The initial doses were $6 \mathrm{MU}$ daily in 37 patients and $3 \mathrm{MU}$ daily in 7 patients, which were subsequently tapered upon suppression of ocular inflammation. Oral corticosteroids were either discontinued or kept below $10 \mathrm{mg}$ daily. The authors reported that 16 patients $(36.4 \%)$ remained free of inflammation during treatment, while 28 patients $(63.6 \%)$ had recurrent flare ups. Overall, $91 \%$ of patients experienced a partial or complete response. Gueudry and coworkers studied 32 patients with sightthreatening uveitis associated with $\mathrm{ABD}$ who failed previous immunosuppressive and corticosteroid therapy. ${ }^{95}$ The patients were treated with 3MU 3 times per week. Inflammation was controlled in 28 patients ( $88 \%$ ) over a mean observation period of 70.6 months. The authors concluded that while the treatment was efficient and safe in the treatment of ABD uveitis, it appeared to be a suspensive therapeutic strategy as relapse occurrence increased following discontinuation of IFN- $\alpha$; nevertheless, weaning of the drug was possible in some patients.

\section{Infliximab}

It has been found that TNF- $\alpha$, a proinflammatory cytokine, is present in the sera of patients with active ABD due to overproduction by elevated numbers of $\mathrm{T}$ lymphocytes and monocytes. ${ }^{96-98}$ In addition, TNF receptors were also found to be elevated in the peripheral blood of ABD patients. ${ }^{97}$ Infliximab (Remicade $^{\circledR}$; Centocor Ortho Biotech Inc.) is a human - murine chimeric TNF- $\alpha$ inhibitor. An IgG monoclonal antibody, it binds to and deactivates TNF- $\alpha$ molecules. An expert panel has put forth the following criteria for the selection of patients eligible for anti-TNF- $\alpha$ therapy: (i) a definite diagnosis of ABD; (ii) presence of active disease, including objective signs of inflammation; (iii) previous failure of drugs that have a documented efficacy in controlling ABD manifestations, combined or not, with low dose corticosteroids $(7.5 \mathrm{mg}$ daily); (iv) presence of contraindications or intolerance to conventional immunomodulatory regimens; (v) absence of contraindications to anti-TNF treatment. ${ }^{99}$ Several studies have demonstrated the efficacy of infliximab therapy in the control of ocular and systemic manifestations of ABD. ${ }^{100-102}$ In a prospective open study, Sfikakis and associates demonstrated an effective remission of acute ocular inflammation following a single infusion of $5 \mathrm{mg} / \mathrm{kg}$ intravenous infliximab in $96 \%$ of patients with ocular ABD. ${ }^{103}$ The authors also found that cystoid macular edema resolved after 28 days of therapy in $90 \%$ of patients. More recently, Niccoli and associates conducted a prospective 24-month follow-up study on 12 consecutive patients with $\mathrm{ABD}$-associated posterior uveitis refractory to other immunomodulatory therapies. ${ }^{104}$ Patients were treated with prednisolone $1 \mathrm{mg} / \mathrm{kg}$ daily with rapid tapering and 9 infliximab infusions $(5 \mathrm{mg} / \mathrm{kg}$ ) for 12 months. At the 12-month visit, 75\% of patients achieved complete steroid-free disease remission with no relapses by week 22 . At the 24 -month visit, $78 \%$ of patients were still in remission. Tognon and coworkers studied 7 patients with sight-threatening relapsing uveitis refractory to previous therapy. ${ }^{105}$ The patients received intravenous infliximab at a dose of 3 to $5 \mathrm{mg} / \mathrm{kg}$, on weeks $0,2,4$ and then every 6 to 8 weeks thereafter, in combination with low-dose prednisone and azathioprine or methotrexate. The mean follow-up period was 23 months, after which the total number of relapses dropped to 6 , compared to the 21 observed in an equivalent period of time before treatment. Visual acuity improved in 4 eyes and remained stable in 9. The authors concluded that infliximab is safe and effective in controlling both the number and intensity of cases of posterior uveitis in ABD patients, allowing the reduction of corticosteroids and other immunosuppressive drugs. However, the authors remarked that ocular and systemic manifestations tended to recur after the treatment was discontinued or when the interval between infliximab infusions was longer than 8 weeks.

\section{Etanercept}

Etanercept (Enbrel ${ }^{\circledR}$; Amgen/Wyeth) is a dimeric fusion protein consisting of the extracellular ligand-binding portion of the human $75 \mathrm{kDa}$ (p75) TNF receptor (TNFR) linked to the Fc portion of human IgG1. ${ }^{33}$ Etanercept is produced by recombinant DNA technology. It consists of 934 amino acids and has an apparent molecular weight of approximately $150 \mathrm{kDa}$ with a good tolerability when administered by subcutaneous injection. ${ }^{106}$

Etanercept is indicated either alone or in combination with other agents in the treatment of the symptoms of rheumatoid arthritis, polyarticular juvenile idiopathic arthritis, psoriatic 
arthritis and ankylosing spondylitis among others. In our experience, however, its effectiveness in controlling ocular inflammation associated with these diseases is limited. On the other hand, studies have shown that etanercept may be beneficial, at least in the short term, in maintaining visual acuity in patients with refractory uveitis secondary to ABD. ${ }^{107}$ A greater response has been noted over other ABD complications such as oral ulcers, nodular and papulopustular skin lesions as well as the arthritis symptoms, though these observations have been inconsistent. ${ }^{108,109}$

Other anti-TNF- $\alpha$ agents, such as infliximab, have shown better ocular results than those seen with etanercept. A recent study at the University of Padova, evaluated the efficacy of anti-TNF- $\alpha$ therapy, in this case infliximab, in 7 patients with severe ocular involvement resistant to previous treatment. ${ }^{110}$ This therapy proved to be safe and effective in controlling both the number and intensity of posterior uveitis flares and the extraocular manifestations of $\mathrm{ABD}$, but ocular and systemic manifestations recurred after drug withdrawal, as was seen in patients treated with etanercept. ${ }^{111}$

\section{Pentoxifylline}

Pentoxifylline is a methylxanthine derivative hemorheological agent widely known for its role in vascular disorders. Yasui and coworkers reported on the use of this drug on three male patients with ABD uveitis. ${ }^{112}$ They found that pentoxifylline successfully improved the patients' clinical symptoms by its ability to alter cell membrane fluidity and membrane-receptor function, leading to decreased release of superoxide radicals by neutrophils. A recent study suggested that pentoxifylline inhibits Vgamma9/Vdelta2 $T$ cell function in $A B D$ in vitro, which raises the possibility that this drug may be of use in dysregulated cell-mediated immunity immunological disorders. ${ }^{113}$

\section{Granulocytapheresis}

Still considered a novel approach to ABD, granulocytapheresis shows promise with its ability to reduce the neutrophil load from the peripheral blood through selective adsorption phereses. The number of studies pertaining to this treatment method remains scarce. There has been a report regarding the successful control of ABD-associated uveitis. ${ }^{114}$

\section{Surgical interventions}

Due to the nature of ABD, the use of systemic immunomodulatory agents alone or in combination with corticosteroids has become the gold standard of treatment. Nonetheless, ophthalmic complications such as glaucoma, macular edema, cataracts, neovascularization and vitreous hemorrhage are not uncommon in ABD patients. It is in dealing with these complications that surgery may play an important role in preventing further visual loss and even restoring useful vision.

Recurrent inflammation as well as prolonged use of corticosteroids may lead to cataract formation. Most of the complications observed following cataract extraction in ABD patients are related to poorly controlled disease prior to surgery. Therefore, it is advised that a patient receives immunosuppressive medication and prophylactic systemic, topical and/or periocular corticosteroids prior to the procedure. ${ }^{115}$ Once at least 3 months control of inflammation has been achieved, cataract extraction and intraocular lens implantation can then be safely performed. The visual outcome depend mainly on the preoperative posterior segment involvement. ${ }^{116-118}$

Glaucoma, either secondary or neovascular, may be a significant cause of visual loss in patients with ABD. As with glaucoma not associated with ocular inflammatory diseases, initial topical hypotensive regimen should be supplemented with systemic therapy if better control of intraocular pressure is called for. In case of poor pressure control despite aggressive medical treatment, surgical intervention must be considered. In this case, either a drainage device (we prefer Ahmed glaucoma valve,${ }^{119}$ though a Molteno tube shunt is a reasonable option $)^{120}$ or trabeculectomy with antimetabolites is employed. ${ }^{121-126}$

Another common complication seen in $\mathrm{ABD}$ patients is vitreous hemorrhage. $\mathrm{ABD}$ vasculopathy results in retinal hypoxia and subsequent production of vascular endothelial growth factors, leading to ocular neovascularization. Patients with repeated episodes of hemorrhages and neovascularization may have severe underlying retinal disease. Vitreous hemorrhage may spontaneously resolve without any intervention. In patients with retinal tractional diseases and repeated vitreous hemorrhages, however, pars plana vitrectomy (PPV) should be considered to try to avoid further damage. One earlier report suggested that PPV had extremely poor outcomes in ABD patients and thus should be avoided. ${ }^{127}$ However, as more advanced vitreoretinal surgical techniques and technologies as well as better medical therapies become available, recent reports have all demonstrated that vitrectomy has a beneficial effect on vision in ABD. ${ }^{128-131}$ In cases of retinal neovascularization, early diagnosis and treatment with retinal photocoagulation may be beneficial, ${ }^{132}$ but some investigators believe that this will lead to production of retinal antigens which may lead to systemic 
sensitization and thus exacerbation of ABD. In addition, laser may not be as effective as certain immunosuppressive agents in treating neovascularization. For instance, Tugal-Tutkun's group found that optic disc neovascularization associated with ABD was more successfully treated with IFN- $\alpha$ than photocoagulation. ${ }^{133}$

\section{Conclusion}

ABD-associated ocular disease remains one of the most difficult diseases an ophthalmologist will encounter in his or her career. Its relentlessly explosive nature and progressive course frequently cause blindness without much warning. Therefore, it is imperative for a clinician to diagnose the disease early and institute aggressive therapy if necessary. While there are a number of treatment options available, none is definitively effective or safe. Care and expertise are needed in the selection and administration of immunomodulatory regimens, and this will likely require a coordinated effort between the ophthalmologist and a chemotherapist. When one faces an especially difficult case, timely referral to a specialist in ocular inflammatory disease and immunology is essential.

\section{Disclosures}

The authors declare no conflicts of interest.

\section{References}

1. Hippocrates. In: Dilsen N, Kaktos, Editor. Third book on epidemiology. Case 7. 1993; p. 209.

2. Adamantiades B. A case of recurrent hypopyon iritis. Medical Society of Athens. 1930;586-593.

3. Behçet H. Uber rezidivierende aphthose, durch ein Virus verursachte Geschwure am Mud, am Auge und an den Genitalien. Derm Wochenschr. 1937;36:1152-1157.

4. Ohno S. Behçet's disease in the World. In: Lehner T, Barnes CG, editors. Recent Advances in Behçet's Disease. London: Royal Society of Medicine Service; 1986.

5. Chajek T, Fainaru M. Behçet's disease: Report of 41 cases and a review of the literature. Medicine. 1975;54(3):179-196.

6. O’Duffy JD: Behçet's disease. In: Kelly WN, Harris ED, Ruddy S, Sledge CB, editors. Textbook of Rheumatology. Philadelphia: WB Saunders; 1985;1174-1178.

7. Mamo JG, Baghdassarian A. Behçet's disease: A report of 28 cases. Arch Ophthalmol. 1964;71:4-14.

8. Shimizu T. Clinical and immunological studies on Behçet's syndrome. Folia Ophthalmol Jpn. 1971;22(10):801-810.

9. Mizuki N, Ohno S, Ando H, et al. A strong association between HLA-B*5101 and Behçet's disease in Greek patients. Tissue Antigen. 1997:50(1):57-60.

10. Ohno S, Ohguchi M, Hirose S, et al. Close association of HLA-Bw51 with Behçet's disease. Arch Ophthalmol. 1982;100(9):1455-1458.

11. Mishima S, Masuda K, Izawa Y, et al. Behçet's disease in Japan: Ophthalmologic aspects. Trans Am Ophthalmol Soc. 1979;76:225-279.

12. Lehner T, Barnes CG. Criteria for diagnosis and classification of Behçet's syndrome. In: Lehner T, Barnes CG, editors. Behçet's Syndrome: Clinical and Immunological Features. Proceedings of a Conference Sponsored by Royal Society of Medicine, February 1979. London: Academic Press. 1979;1-9.
13. Numaga J, Matsuki M, Mochizuki M, et al. An HLA-D region restriction fragment associated with refractory Behçet's disease. Am JOphthalmol. 1988;105(5):528-533.

14. Shikano S. Ocular pathology of Behçet's syndrome. In: Monacelli M, Nazzaro P, editors. International Symposium on Behçet's Disease. New York: Karger, Basel. 1966;111-136.

15. Lakhanpal SH, Tani K, Lie JT, et al. Pathologic features of Behçet's syndrome: A review of Japanese autopsy registry data. Hum Pathol. 1985;16(8):790-795.

16. Behçet's Disease Research Committee of Japan. Behçet's disease: Guide to diagnosis of Behçet's disease. Jpn J Ophthalmol. 1974;18:291-294.

17. International Study Group for Behçet's Disease. Criteria for diagnosis of Behçet's disease. Lancet. 1990;335(8697):1078-1080.

18. Pande I, Uppal S, Kailash S, et al. Behçet's disease in India: A clinical, immunological, immunogenetic and outcome study. Br J Rheumatol. 1995;34(9):825-830.

19. Benamour S, Zeroual B, Bennis R, et al. Maladie de Behçet. 316 cas. La Presse Med. 1990;19(32):1485-1489.

20. Dilsen N, Konice K, Aral O, et al. Risk factors for vital organ involvement in Behçet's disease. In: Godeau P, Wechsler B, editors. Behçet's Disease. New York: Elsevier Science. 1993;165-169.

21. Gharibdoost F, Davatchi F, Shahram F, et al. Clinical manifestations of Behçet's disease in Iran: Analysis of 2176 casese. In: Godeau P, Wechsler B, editors. Behçet's Disease. New York: Elsevier Science, 1993;153-158.

22. Imai Y. Studies on prognosis and symptoms of Behçet's disease in long-term observation. Jpn J Clin Ophthalmol. 1971;25:665-694.

23. Benezra D, Cohen E. Treatment and visual prognosis in Behçet's disease. Br J Opthalmol. 1986 Aug;70(8):589-592.

24. Kaklamai VG, Kaklamanis PG. Treatment of Behçet's disease: an update. Semi Arthritis Rheum. 2001;30:299-312.

25. Toker E, Kazokoglu H, Acar N. High dose intravenous steroid therapy for severe posterior segment uveitis in Behçet's disease. $\mathrm{Br} J$ Ophthalmol. 2002 May;86(5):521-523.

26. Evereklioglu C. Managing the symptoms of Behçet's disease. Expert Opin Pharmacother. 2004;5(2):317-328.

27. Tugal-Tutkun I, Önal S, Altan Yaycioglu R, et al. Uveitis in Behçet's disease: an analysis of 880 patients. Am J Ophthalmol. 2004;138(3):373-380.

28. Standarization of Uveitis Nomenclature (SUN) Working Group. Standarization of uveitis nomenclature for reporting clinical data: results of the First International Workshop. Am J Ophthalmol. 2005 Sep;140(3):509-516.

29. Yoshikawa K, Ichiishi A, Kotabe S, et al. Posterior sub-Tenon's space injection of repository corticosteroids in uveitis patients with cystoid macular edema. Nippon Ganka Gakkai Zasshi. 1993;97(9):1070-1074.

30. Rothova A. Medical treatment of cystoid macular edema. Ocul Immunol Inflamm. 2002;10(4):239-246.

31. Fine H, Baffi J, Reed GF, et al. Aqueous humor and plasma vascular endothelial growth factor in uveitis associated cystoid macular edema. Am J Ophthalmol. 2001;132(5):794-796.

32. Cordero-Coma M, Sobrin L, Onal S, et al. Intravitreal bevacizumab for treatment of uveitic macular edema. Ophthalmology. 2007;114(8): 1574-1579.

33. Okada AA. Immunomodulatory therapy for ocular inflammatory disease: a basic manual and review of the literature. Ocul Immunol Inflamm. 2005;13(5):335-351.

34. Kötter I, Dürk H, Saal J, Fierlbeck G, Pleyer U, Ziehut M. Therapy of Behçet's disease. Ger J Ophthalmol. 1996;5(2):92-97.

35. Hamuryudan V, Ozyazgan Y, Hizli N, et al. Azathioprine in Behçet's syndrome: effects on long-term prognosis. Arthritis Rheum. 1997;40(4):769-774.

36. Greenwood AJ, Stanford MR, Graham EM. The role of azathioprine in the management of retinal vasculitis. Eye. 1998;12(5):783-788.

37. Sakane T, Takeno M, Suzuki N, Inaba G, et al. Behçet's disease. NEngl J Med. 1999;341(17):1284-1291. 
38. Foster CS, Baeyer JC, Raizman MB. Therapeutic response to systemic immunosuppressive chemotherapy agents in patients with Behçet's syndrome affecting the eyes. In: O’Duffy KE, editor. Behçet's Disease: Basic and Clinical Aspects. New York: Marcel Dekker. 1991;581-588.

39. Jabs DA, Rosenbaum JT, Foster CS, et al. Guidelines for the use of immunosuppressive drugs in patients with ocular inflammatory disorders: recommendations of an expert panel. Am J Ophthalmol. 2000;130(4):492-513.

40. Davatchi F, Shahram F, Chams H, et al. High dose methotrexate for ocular lesions of Behçet's disease. Preliminary short-term results. Adv Exp Med Biol. 2003;528:579-584.

41. Ghate JV, Jorizzo JL. Behçet's disease and complex aphthosis. J Am Acad Dermatol. 1999;40(1):1-18; quiz 19-20.

42. Hirohata S, Suda H, Hashimoto T. Low-dose weekly methotrexate for progressive neuropsychiatric manifestations in Behçet's disease. J Neurol Sci. 1998;159(2):181-185.

43. Weinblatt ME. Toxicity of low dose methotrexate in rheumatoid arthritis. J Rheumatol Suppl. 1985;12 Suppl 12:35-39.

44. Kremer JM, Alarcón GS, Lightfoot RW Jr, et al. Methotrexate for rheumatoid arthritis. Suggested guidelines for monitoring liver toxicity. American College of Rheumatology. Arthritis Rheum. 1994;37(3): 316-328.

45. Walker AM, Funch D, Dreyer NA, et al. Determinants of serious liver disease among patients receiving low-dose methotrexate for rheumatoid arthritis. Arthritis Rheum. 1993;36(3):329-335.

46. Kempen JH, Gangaputra S, Daniel E, et al. Long-term risk of malignancy among patients treated with immunosuppressive agents for ocular inflammation: a critical assessment of the evidence. $A m J$ Ophthalmol. 2008;146(6):802-812 e1.

47. Yu T, Yu TF. Milestones in the treatment of gout. Am J Med. 1974; 56(5):676-685.

48. Ehrenfeld M, Levy M, Bar Eli M, Gallily R, Eliakim M. Effect of colchicine on polymorphonuclear leucocyte chemotaxis in human volunteers. Br J Clin Pharmacol. 1980;10(3):297-300.

49. Malawista SE. The action of colchicine in acute gouty arthritis. Arthritis Rheum, 1975;18(6 Suppl):835-846.

50. Pesanti EL, SG Axline. Colchicine effects on lysosomal enzyme induction and intracellular degradation in the cultivated macrophage. $J$ Exp Med. 1975;141(5):1030-1046.

51. Frayha RA. Arthropathy of Behçet's disease with marked synovial pleocytosis responsive to colchicine. Arthritis Rheum. 1982;25(2):235-236.

52. Ando K, Fujino Y, Hijikata K, Izawa Y, Masuda K. Epidemiological features and visual prognosis of Behçet's disease. Jpn J Ophthalmol. 1999;43(4):312-317.

53. Matsumura N, Mizushima Y. Leucocyte movement and colchicine treatment in Behçet's disease. Lancet. 1975;2(7939):813.

54. Mizushima Y, Matsumura N, Mori M, et al. Colchicine in Behçet's disease. Lancet. 1977;2(8046):1037.

55. Raynor A, Askari AD. Behçet's disease and treatment with colchicine. J Am Acad Dermatol. 1980;2(5):396-400.

56. Fontes V, Machet L, Huttenberger B, Lorette G, Vaillant L. [Recurrent aphthous stomatitis: treatment with colchicine. An open trial of 54 cases]. Ann Dermatol Venereol. 2002;129(12):1365-1369.

57. Mizushima Y. Behçet's disease. Curr Opin Rheumatol. 1991; 3(1):32-35.

58. Masuda K, Nakajima A, Urayama A, Nakae K, Kogure M, Inaba G. Double-masked trial of cyclosporin versus colchicine and longterm open study of cyclosporin in Behçet's disease. Lancet. 1989; 1(8647):1093-1096.

59. Evereklioglu C. Current concepts in the etiology and treatment of Behçet disease. Surv Ophthalmol. 2005;50(4):297-350.

60. Gilman AG GL, Rall TW, Murad F. The Pharmacological Basis of Therapeutics. New York: Macmillan Publishing Company. 1985;709.

61. Newell DR, Calvert AH, Harrap KR, McElwain TJ. Studies on the pharmacokinetics of chlorambucil and prednimustine in man. Br JClin Pharmacol. 1983;15(2):253-258.
62. Mamo JG, Azzam SA. Treatment of Behçet's disease with chlorambucil. Arch Ophthalmol. 1970;84(4):446-450.

63. Tessler HH, Jennings T. High-dose short-term chlorambucil for intractable sympathetic ophthalmia and Behçet's disease. $\mathrm{Br} J$ Ophthalmol. 1990;74(6):353-357.

64. Mudun BA, Ergen A, Ipcioglu SU, Burumcek EY, Durlu Y, Arslan MO Short-term chlorambucil for refractory uveitis in Behçet's disease. Ocul Immunol Inflamm. 2001;9(4):219-229.

65. Goldstein DA, Fontanilla FA, Kaul S, Sahin O, Tessler HH. Long-term follow-up of patients treated with short-term high-dose chlorambucil for sight-threatening ocular inflammation. Ophthalmology. 2002;109(2):370-377.

66. Miserocchi E, Baltatzis S, Ekong A, Roque M, Foster CS. Efficacy and safety of chlorambucil in intractable noninfectious uveitis: the Massachusetts Eye and Ear Infirmary experience. Ophthalmology. 2002;109(1):137-142.

67. Grupe WE. Chlorambucil in steroid-dependent nephrotic syndrome. J Pediatr. 1973;82(4):598-606.

68. Guesry P, Lenoir G, Broyer M. Gonadal effects of chlorambucil given to prepubertal and pubertal boys for nephrotic syndrome. J Pediatr. 1978;92(2):299-303.

69. Richter P, Calamera JC, Morgenfeld MC, Kierszenbaum AL, Lavieri JC, Mancini RE. Effect of chlorambucil on spermatogenesis in the human with malignant lymphoma. Cancer. 1970;25(5):1026-1030.

70. Callis L, Nieto J, Vila A, Rende J. Chlorambucil treatment in minimal lesion nephrotic syndrome: a reappraisal of its gonadal toxicity. J Pediatr. 1980;97(4):653-656.

71. Moore MJ. Clinical pharmacokinetics of cyclophosphamide. Clin Pharmacokinet. 1991;20(3):194-208.

72. Grochow LB, Colvin M. Clinical pharmacokinetics of cyclophosphamide Clin Pharmacokinet. 1979;4(5):380-394.

73. Shek LP, Lim DL. Thalidomide in Behçet's disease. Biomed Pharmacother. 2002;56(1):31-35.

74. Calabrese L, Fleischer AB. Thalidomide: current and potential clinical applications. Am J Med. 2000;108(6):487-495.

75. Rabinowitz R, Katz G, Rosner M, Pri-Chen S, Spierer A. The effect of thalidomide on neovascularization in a mouse model of retinopathy of prematurity. Graefes Arch Clin Exp Ophthalmol. 2008;246(6): 843-848.

76. Lambert K, Ward J. The use of thalidomide in the management of bleeding from a gastric cancer. Palliat Med. 2009;23(5):473-475.

77. Alberto SF, Felix J, de Deus J. Thalidomide for the treatment of severe intestinal bleeding. Endoscopy. 2008;40(9):788; author reply 789.

78. Bauditz J, Lochs H. Angiogenesis and vascular malformations: antiangiogenic drugs for treatment of gastrointestinal bleeding. World J Gastroenterol. 2007;13(45):5979-5984.

79. Dabak V, Kuriakose P, Kamboj G, Shurafa M. A pilot study of thalidomide in recurrent GI bleeding due to angiodysplasias. Dig Dis Sci. 2008;53(6):1632-1635.

80. Gardner-Medwin JM, Smith NJ, Powell RJ. Clinical experience with thalidomide in the management of severe oral and genital ulceration in conditions such as Behçet's disease: use of neurophysiological studies to detect thalidomide neuropathy. Ann Rheum Dis. 1994;53(12):828-832.

81. Eisenbud L, Horowitz I, Kay B. Recurrent aphthous stomatitis of the Behçet's type: successful treatment with thalidomide. Oral Surg Oral Med Oral Pathol. 1987;64(3):289-292.

82. Treves R, Arnaud M, Jacob P, et al. [Speculative ameloriation of arthritis in Behçet disease with thalidomide. A case report]. Rev Rhum Mal Osteoartic. 1984;51(10):585.

83. Hamza MH. Treatment of Behçet's disease with thalidomide. Clin Rheumatol. 1986;5(3):365-371.

84. Mellin GW, Katzenstein M. The saga of thalidomide. Neuropathy to embryopathy, with case reports of congenital anomalies. $N$ Engl J Med. 1962;267:1238-1244.

85. Ochonisky S, Verroust J, Bastuji-Garin S, Gherardi R, Revuz J. Thalidomide neuropathy incidence and clinico-electrophysiologic findings in 42 patients. Arch Dermatol. 1994;130(1):66-69. 
86. De Tran QH, Guay E, Chartier S, Tousignant J. Tacrolimus in dermatology. J Cutan Med Surg. 2001;5(4):329-335.

87. Dick AD. Experimental approaches to specific immunotherapies in autoimmune disease: future treatment of endogenous posterior uveitis? Br J Ophthalmol. 1995;79(1):81-88.

88. Mochizuki M. Immunotherapy for Behçet's disease. Int Rev Immunol. 1997;14(1):49-66.

89. Figueroa MS, Ciancas E, Orte L. Long-term follow-up of tacrolimus treatment in immune posterior uveitis. Eur J Ophthalmol. 2007;17(1):69-74.

90. Sloper CM, Powell RJ, Dua HS. Tacrolimus (FK506) in the treatment of posterior uveitis refractory to cyclosporine. Ophthalmology. 1999;106(4):723-728.

91. Hogan AC, McAvoy CE, Dick AD, Lee RW. Long-term efficacy and tolerance of tacrolimus for the treatment of uveitis. Ophthalmology. 2007;114(5):1000-1006

92. Belardelli F, Gresser I. The neglected role of type I interferon in the T-cell response: implications for its clinical use. Immunol Today. 1996;17(8):369-372.

93. Feron EJ, Rothova A, van Hagen PM, Baarsma GS, SuttorpSchulten MS. Interferon-alpha $2 \mathrm{~b}$ for refractory ocular Behçet's disease. Lancet. 1994;343(8910): 1428.

94. Tugal-Tutkun I, Guney-Tefekli E, Urgancioglu M. Results of interferon-alfa therapy in patients with Behçet uveitis. Graefes Arch Clin Exp Ophthalmol. 2006;244(12):1692-1695.

95. Gueudry J, Wechsler B, Terrada C, et al. Long-term efficacy and safety of low-dose interferon alpha2a therapy in severe uveitis associated with Behçet disease. Am J Ophthalmol. 2008;146(6): $837-844 \mathrm{e} 1$.

96. Freysdottir J, Lau S, Fortune F. Gammadelta T cells in Behçet's disease (BD) and recurrent aphthous stomatitis (RAS). Clin Exp Immunol. 1999;118(3):451-457.

97. Turan B, Gallati H, Erdi H, Gurler A, Michel BA, Villiger PM. Systemic levels of the T cell regulatory cytokines IL-10 and IL-12 in Bechcet's disease; soluble TNFR-75 as a biological marker of disease activity. J Rheumatol. 1997;24(1):128-132.

98. Haznedaroglu E, Karaaslan Y, Buyukasik Y, et al. Selectin adhesion molecules in Behçet's disease. Ann Rheum Dis. 2000;59(1):61-63.

99. Sfikakis PP, Markomichelakis N, Alpsoy E, et al. Anti-TNF therapy in the management of Behçet's disease - review and basis for recommendations. Rheumatology (Oxford). 2007;46(5): 736-741.

100. Goossens PH, Verburg RJ, Breedveld FC. Remission of Behçet's syndrome with tumour necrosis factor alpha blocking therapy. Ann Rheum Dis. 2001;60(6):637.

101. Sfikakis PP. Behçet's disease: a new target for anti-tumour necrosis factor treatment. Ann Rheum Dis. 2002;61 Suppl 2:ii51-ii53.

102. Sfikakis PP, Theodossiadis PG, Katsiari CG, Kaklamanis P, Markomichelakis NN. Effect of infliximab on sight-threatening panuveitis in Behçet's disease. Lancet. 2001;358(9278):295-296.

103. Sfikakis PP, Kaklamanis PH, Elezoglou A, et al. Infliximab for recurrent, sight-threatening ocular inflammation in AdamantiadesBehçet disease. Ann Intern Med. 2004;140(5):404-406.

104. Niccoli L, Nannini C, Benucci M, et al. Long-term efficacy of infliximab in refractory posterior uveitis of Behçet's disease: a 24-month follow-up study. Rheumatology (Oxford). 2007;46(7): 1161-1164.

105. Tognon S, Graziani G, Marcolongo R. Anti-TNF-alpha therapy in seven patients with Behçet's uveitis: advantages and controversial aspects. Ann NY Acad Sci. 2007;1110:474-484.

106. Maini RN, Taylor PC. Anti-cytokine therapy for rheumatoid arthritis. Ann Rev Med. 2000;51:207-229.

107. Thomas-Golbanov C, Sridharan S. Novel therapies in vasculitis. Exp Opin Invest Drug. 2001;10:1279-1289.

108. Melikoglu M, Özyazgan Y, Fresko I, et al. The response of treatment resistant uveitis in Behçet's syndrome (BS) to a TNF- $\alpha$ blocker, etanercept: an open study. Arthritis Rheum. 2002;46:181.
109. Evans CA, Jellis J, Hughes SP, et al. Tumor necrosis factor- $\alpha$, interleukin-6, and interleukin-8 secretion and the acute-phase response in patients with bacterial and tuverculous osteomyelitis. J Infect Dis. 1998;177:1582-1587.

110. Yücel AE, Kart-Köseoglu H, Akova YA, et al. Failure of infliximab treatment and occurrence of erythema nodosum during therpy in two patients with Behçet's disease. Rheumatology. 2004;43:394-396.

111. Tognon S, Graziani G, Marcolongo R. Anti-TNF-alpha therapy in seven patients with Behçet's uveitis: advantages and controversial aspects. Ann NY Acad Sci. 2007;1110:474-484

112. Yasui K, Ohta K, Kobayashi M, Aizawa T, Komiyama A. Successful treatment of Behçet disease with pentoxifylline. Ann Intern Med. 1996;124(10):891-893.

113. Accardo-Palumbo A, Ferrante A, Ciccia F, et al. Pentoxifylline inhibits Vgamma9/Vdelta2 T lymphocyte activation of patients with active Behçets disease in vitro. Int J Immunopathol Pharmacol. 2007;20(3):601-606.

114. Namba K, Sonoda KH, Kitamei H, et al. Granulocytapheresis in patients with refractory ocular Behçet's disease. J Clin Apher. 2006;21(2):121-128.

115. Rojas B, Zafirakis P, Foster CS. Cataract surgery in patients with uveitis. Curr Opin Ophthalmol. 1997;8:6-12.

116. Sullu Y, Oge I, Erkan D. The results of cataract extraction and intraocular lens implantation in patients with Behçet's disease. Acta Ophthalmol Scand. 2000;78(6):680-683.

117. Berker N, Soykan E, Elgin U, Ozkan SS. Phacoemulsification cataract extraction and intraocular lens implantation in patients with Behçet's disease. Ophthalmic Surg Lasers Imaging. 2004;35(3):215-218.

118. Kadayifcilar S, Gedik S, Eldem B, Irkec M. Cataract surgery in patients with Behçet's disease. J Cataract Refract Surg. 2002;28(2):316-320.

119. Da Mata A, Burk SE, Netland PA, Baltatzis S, Christen W, Foster CS. Management of uveitic glaucoma with Ahmed glaucoma valve implantation. Ophthalmology. 1999;106(11):2168-2172.

120. Hill RA, Nguyen QH, Baerveldt G, et al. Trabeculectomy and Molteno implantation for glaucomas associated with uveitis. Ophthalmology. 1993;100(6):903-908.

121. Jampel HD, Jabs DA, Quigley HA. Trabeculectomy with 5- fluorouracil for adult inflammatory glaucoma. Am J Ophthalmol. 1990;109(2): 168-173.

122. Patitsas CJ, Rockwood EJ, Meisler DM, Lowder CY. Glaucoma filtering surgery with postoperative 5-fluorouracil in patients with intraocular inflammatory disease. Ophthalmology. 1992;99(4):594-599.

123. Prata JA Jr, Neves RA, Minckler DS, Mermoud A, Heuer DK. Trabeculectomy with mitomycin $\mathrm{C}$ in glaucoma associated with uveitis. Ophthalmic Surg. 1994;25(9):616-660.

124. Towler HM, McCluskey P, Shaer P, Lightman S. Long-term follow-up of trabeculectomy with intraoperative 5-fluorouracil for uveitis-related glaucoma. Ophthalmology. 2000;107(10):1822-1828.

125. Ceballos EM, Beck AD, Lynn MJ. Trabeculectomy with antiproliferative agents in uveitic glaucoma. J Glaucoma. 2002;11(3):189-196.

126. Yalvac IS, Sungur G, Turhan E, Eksioglu U, Duman S. Trabeculectomy with mitomycin-C in uveitic glaucoma associated with Behçet's disease. J Glaucoma. 2004;13(6):450-453.

127. Ozdemir O, Erkam N, Bakkaloglu A. Results of pars plana vitrectomy in Behçet's disease. Ann Ophthalmol. 1988;20(1):35-38.

128. Soylu M, Demircan N, Pelit A. Pars plana vitrectomy in ocular Behçet's disease. Int Ophthalmol. 2001;24(4):219-223.

129. Ozerturk Y, Bardak Y, Durmus M. Vitreoretinal surgery in Behçet's disease with severe ocular complications. Acta Ophthalmol Scand. 2001;79(2):192-196.

130. Sullu Y, Alotaiby H, Beden U, Erkan D. Pars plana vitrectomy for ocular complications of Behçet's disease. Ophthalmic Surg Lasers Imaging. 2005;36(4):292-297.

131. Krause L, Altenburg A, Bechrakis NE, Willerding G, Zouboulis CC, Foerster MH. Intraocular surgery under systemic interferon-alpha therapy in ocular Adamantiades-Behçet's disease. Graefes Arch Clin Exp Ophthalmol. 2007;245(11):1617-1621. 
132. Atmaca LS. Experience with photocoagulation in Behçet's disease. Ophthalmic Surg. 1990;21:571-576.

133. Tugal-Tutkun I, Onal S, Altan-Yaycioglu R, Kir N, Urgancioglu M. Neovascularization of the optic disc in Behçet's disease. Jpn J Ophthalmol. 2006;50(3):256-265.

134. Newman NM, Hoyt WF, Spencer WH. Macula-sparing monocular blackouts: Clinical and pathologic investigation of intermittent choroidal vascular insufficiency in a case of periarteritis nodosa. Arch Ophthalmol. 1974;91(5):367-370.
135. Gold DH. Ocular manifestations of connective tissue (collagen) diseases. In: Tasman W, Jaeger AE, editors. Duane's Clinical Ophthalmology. Philadelphia: J.B. Lippincott. 1989; 5:17-19.

\section{Publish your work in this journal}

Clinical Ophthalmology is an international, peer-reviewed journal covering all subspecialties within ophthalmology. Key topics include: Optometry; Visual science; Pharmacology and drug therapy in eye diseases; Basic Sciences; Primary and Secondary eye care; Patien Safety and Quality of Care Improvements. This journal is indexed on

\section{Dovepress}

PubMed Central and CAS, and is the official journal of The Society of Clinical Ophthalmology (SCO). The manuscript management system is completely online and includes a very quick and fair peer-review system, which is all easy to use. Visit http://www.dovepress.com/ testimonials.php to read real quotes from published authors. 